\title{
Evaluation of morphological changes produced by orifice opener systems using computerized tomography (CT)
}

\author{
Adela Hervas ${ }^{1}$, Leopoldo Forner ${ }^{2}$, Carmen Llena ${ }^{3,4}$, Eduardo Zaragoza ${ }^{5}$ \\ ${ }^{1}$ Associated Professor. Universidad CEU - Cardenal Herrera. Moncada (Spain) \\ ${ }^{2}$ Professor. Department of Stomatology. Universitat de Valencia. Valencia (Spain) \\ ${ }^{3}$ Associated Professor. Department of Stomatology. Universitat de Valencia. Valencia (Spain) \\ ${ }^{4}$ Valencian Public Health Service (Spain) \\ ${ }^{5}$ ERESA (Spain)
}

\author{
Correspondence: \\ Clínica Odontológica. \\ Universitat de Valencia. \\ C. Gasco Oliag, 1 \\ 46010 Valencia (Spain) \\ forner@uv.es
}

Received: 19/01/2009 Accepted: 20/05/2009

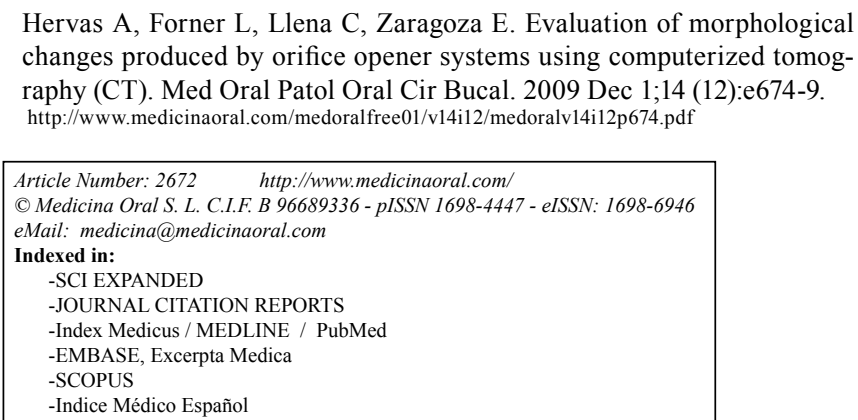

Hervas A, Forner L, Llena C, Zaragoza E. Evaluation of morphological changes produced by orifice opener systems using computerized tomography (CT). Med Oral Patol Oral Cir Bucal. 2009 Dec 1;14 (12):e674-9. http://www.medicinaoral.com/medoralfree01/v14i12/medoralv14i12p674.pdf

Article Number: $2672 \quad$ http://www.medicinaoral.com/

(C) Medicina Oral S. L. C.I.F. B 96689336 - pISSN 1698-4447 - eISSN: $1698-6946$

eMail: medicina@medicinaoral.com

Indexed in:

-SCI EXPANDED

-JOURNAL CITATION REPORTS

-Index Medicus / MEDLINE / PubMed

-EMBASE, Excerpta Medica

-SCOPUS

-Indice Médico Español

\begin{abstract}
Objectives: To evaluate modifications in root canal morphology following instrumentation with orifice openers using Computerized Tomography (CT). Study design: Experimental in vitro study. A preoperative CT was performed on 49 molars to measure the root canal cross-sections. After preparing the canals with 6 different nickel-titanium (Ni-Ti) rotary system orifice opener type instruments and Gates Glidden burs, a further CT was made and compared with the preoperative one. Kruskal-Wallis and ANOVA statistical analysis were used. Results: Gates Glidden burs were significantly more aggressive in the coronal portion of the canals, although all the instruments removed more dental tissue in the most coronal of the sections studied. Bucco-lingual diameters were modified more than the mesio-distal ones. The stainless steel instruments used lead to greater modifications being required in the canals than those made of nickel-titanium. The ProFile system instruments were observed to be those that caused the least amount of change. Conclusions: Stainless steel burs are more aggressive than new orifice openers without significant differences observed between Ni-Ti instruments.
\end{abstract}

Key words: Computerized tomography, endodontics, rotary instruments, Gates-Glidden.

\section{Introduction}

In vitro studies of the anatomy of root canals and their modification after instrumentation have employed many methods: conventional or contrast radiography, serial cuts, using blocks of resin (1) and others.

In 1990, Tachibana and Matsumoto (2) introduced computerised tomography (CT), which can give a three-dimensional image of the root canal, adding the advantage of conforming a non-destructive technique capable of comparing root before and after instrumentation. In this field, a number of studies have employed these threedimensional techniques to assess the anatomy of the crown and root (3) and the modifications to the canals caused by different endodontic instruments (4).

Nickel-titanium (Ni-Ti) endodontic instruments, with different tapers have pointed a change in the endodontic therapy. They can better shape root canal surfaces, avoiding or, at least, minimizing elbows, zippers, perfo- 
rations and other root canal non-desired modifications, employing a less working time than hand instruments. Some new Ni-Ti instruments have widened taper, so they produce a bigger expansion of the coronal aspect of the root canal, allowing the following instruments work (5). In addition, this coronal widening reduces the risk of canal anatomy modification.

There is a lack of information about coronal third canal morphology changes produced by orifice shapers instruments in comparison to other features of these instruments as changes in working length or influence in the behaviour of the following shaping instruments $(6,7)$. The goal of orifice openers instruments is to widen the root canal coronal third in order to permit a better access of shaping instruments to the medium and apical root canal thirds. Clinical evidence confirm that, but a few number of studies are focused on changes in morphological changes in the coronal area. CT has not been frequently used to analyse how endodontic instruments work in spite of allowing to get pre- and postoperative images in differently oriented cutting planes that can be easily compared.

The aim of this paper is to evaluate morphological changes of the coronal root canal third, at different levels (bucal-lingual, mesial-distal and axial) produced by orifice openers instruments, using a non-invasive technique (CT).

\section{Materials and Methods}

49 mandibular molars were chosen, their roots where completely formed, without resorptions or root canal calcifications; all of them had slight curvatures. The remaining soft tissues were removed and teeth were kept in a saline medium. These teeth presented canals of different shapes: narrow and rounded in the case of the mesial canals, wide and oval in that of the distal canal or canals. All canals where instrumented. Canals inclusion and exclusion criteria for the analysis, where as follow: when a molar presented two mesials and one distal canal, the three canals where included in the analysis, when the molars only had two root canals (one mesial and one distal) it was decided not to select the mesial canals for analysis and when two distal canals were found, it was decided to take the disto-bucal canal as equivalent to the distal canal found in mandibular molars with three canals (8). Amalgam fillings restorations were removed because metallic surfaces cause metal artefacts in the images.

The canals selected numbered 145 and were randomly divided into 7 study groups; 12 canals without patency were rejected, making $n=19$ for each of the sample groups. Prior to canal preparation, one mark was made on the external surface of each tooth at crown-root junction and a further 3 at $2 \mathrm{~mm}$ intervals in the direction of the apex, as reference points for the subsequent measurements, so level "a" was the deepest one, and levels "b" and "c" the middle and coronal ones respectively. Roots were embedded in blocks of resin to avoid movements during acquisitions and to get them always in the same beam projection. The preoperative images were then acquired with a multidetector helical CT system providing isotropic voxels, the GE Medical Systems Lightspeed 16 CTS1_OC0 (General Electric Medical Systems, Frankfurt, Germany), under the following conditions: $120 \mathrm{kV}$, $290 \mathrm{~mA}$, slice thickness $=0.625 \mathrm{~mm}, \mathrm{SFOV}=25 \mathrm{~cm}$, edge filter, matrix $=512 \times 512$, then viewed with the Advantage Workstation AW4.1_04 (General Electric Medical Systems, Frankfurt, Germany), with a resolution of $0.2 \mathrm{~mm}, \mathrm{DFOV}=1.4 \mathrm{~cm}, \mathrm{WW}=7500, \mathrm{WL}=2800$. Each canal was measured at each of the three most apical marks for 9 different measurements (in millimetres except for the canal surface area, which was measured in $\mathrm{mm}^{2}$ ): A, maximum canal depth or labio-lingual diameter of the canal; B, maximum canal width or mesio-distal diameter of the canal; C, canal surface area; D, total root width or mesio-distal diameter of the root measured at the level of maximum canal width; E, distance from the point of intersection of the maximum canal depth and maximum canal width to the exterior of the root, measured horizontally; F, distance from the exterior of the canal to the exterior of the root, measured horizontally at the same height as D and E; G, total root depth or labio-lingual diameter of the root measured at the level of maximum canal depth; $\mathrm{H}$, distance from the point of intersection of the maximum canal depth and maximum canal width to the exterior of the root, measured vertically; I, distance from the exterior of the canal to the exterior of the root, measured horizontally at the same height as $\mathrm{G}$ and $\mathrm{H}$, on the same wall as $\mathrm{H}$ (Fig. 1).

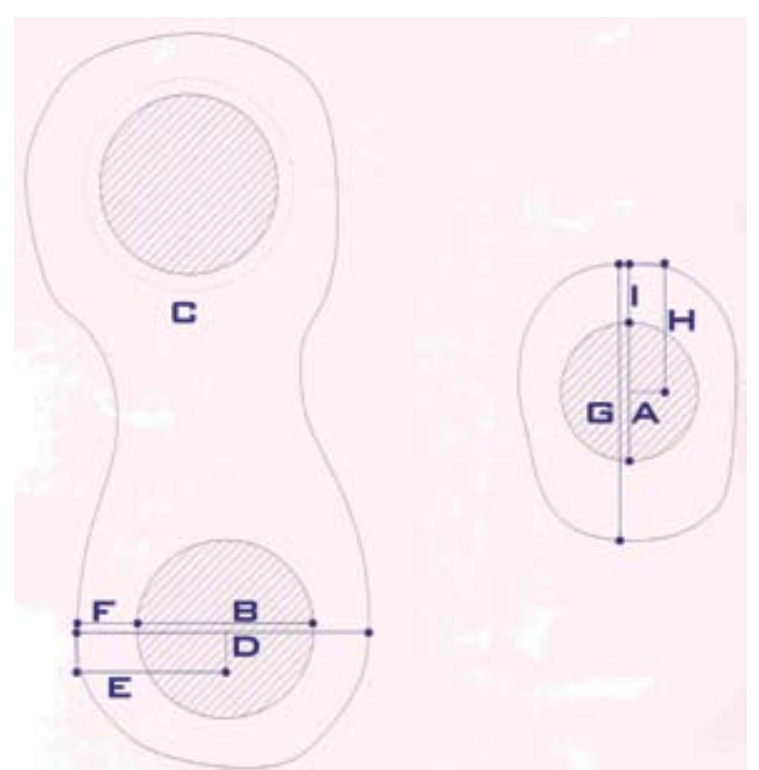

Fig. 1. Different measurements made in each canal at all the height levels studied, in mm, except for surface area (measurement C) $-\mathrm{mm}^{2}$-. 
Table 1. Used instruments.

\begin{tabular}{|c|c|c|c|c|}
\hline Instruments & Manufacturer & Files (1) & Length (2) & Taper \\
\hline GT & $\begin{array}{l}\text { Dentsply/Maillefer,Ballaigues, Swit- } \\
\text { zerland }\end{array}$ & $3,2,1$ & 21 & .12 \\
\hline ProTaper & $\begin{array}{l}\text { Dentsply/Maillefer,Ballaigues, Swit- } \\
\text { zerland }\end{array}$ & $\mathrm{SX}, \mathrm{S} 1, \mathrm{~S} 2$ & $19,21,21$ & variable \\
\hline K3 Endo & Sybron Endo, Orange-CA-, USA & 25 & 17 & $.1, .08$ \\
\hline MFile & Komet, Lemgo, Germany & 1 & 19 & .06 \\
\hline ProFile & $\begin{array}{l}\text { Dentsply/Maillefer,Ballaigues, Swit- } \\
\text { zerland }\end{array}$ & $3,2,1$ & 19 & $.06, .06, .05$ \\
\hline $\begin{array}{l}\text { Quantec series } \\
2000\end{array}$ & Tycom Inc, Irvine -CA-, USA & $1,2,3$ & 17 & $.12, .10, .08$ \\
\hline $\begin{array}{l}\text { Gates Glidden } \\
\text { burs }\end{array}$ & $\begin{array}{l}\text { Dentsply/Maillefer,Ballaigues, Swit- } \\
\text { zerland }\end{array}$ & $3,2,1$ & 3 & \\
\hline
\end{tabular}

(1) Instruments sequence. (2) Cutting length in $\mathrm{mm}$.

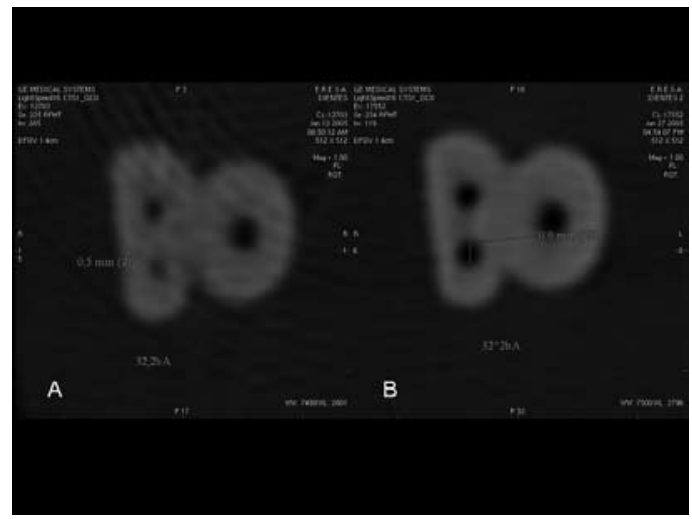

Fig. 2. A CT image of a molar section showing three canals. A. Preoperative image. B. Postoperative image.

After opening and locating the canals and establishing a glide path, the canals were divided into 7 groups and the coronal sections of each were prepared with the orifice openers from one of the sets of endodontic instruments described in table 1 (6 Rotary nickel-titanium -NiTiand Gates Glidden instruments).

Postoperative images were obtained under the same conditions as the preoperative ones and both were compared (Fig. 2 A and B). The rotary instruments were mounted in an endodontic contraangle 16:1 hand piece (Anthogyr, Sallanches, Switzerland) and driven by a TCM Endo motor (Nouvag AG, Goldach, Switzerland) at $300 \mathrm{rpm}$ (except the Gates Glidden burs, which were used at $8000 \mathrm{rpm}$ ).

All instrumentation was performed according to each manufacturer's instructions, so any file was forced into the canal. A single operator instrumented all canals.

To analyse inter-observer agreement, $10 \%$ of the measurements (in both the preoperative and the postoperative observations) were repeated at random and the intra-class correlation coefficient was used.
Pre- and postoperative measurements differences were assess at each level and compared through the Kruskal Wallis non parametric test in each canal. The variables that exhibited statistically significant differences $(p<0.05)$ were analysed using ANOVA with a post-hoc Tukey comparison to determine the groups of instruments among which the differences were significant.

\section{Results}

As regards the reliability of the results, $87.9 \%$ of the preoperative measurements were identical and the intra-class correlation coefficient was 0.9 . In the postoperative measurements, $89 \%$ were identical and the intra-class correlation coefficient was 0.91 .

The table 2 shows for the different instruments, the levels and measurements showing statistically differences.

The disto-bucal canal group (1) presented statistically significant differences in measurements $\mathrm{B}$ and $\mathrm{C}$ at level a. At level $\mathrm{b}$ there were differences in measurement $\mathrm{C}$ and at level $\mathrm{c}$ in measurement $\mathrm{E}$. In mesio-bucal canals (2), most of the measurements with statistically significant differences were encountered at level $b$ (measurements B, C and F). At level $\mathrm{c}$ the differences appeared in measurements $\mathrm{C}$ and $\mathrm{E}$; at level a, none of the measurements showed any differences between the different instruments used. The mesio-lingual canals (3) also presented no significant differences at level a. Level $b$ was where the greatest number of data with significant differences between the instruments employed in the study appeared (in measurements A, B and C). At measurement level c, the significant differences were found in the B measurements. No significant differences between any of the systems studied were found at any level in the disto-lingual canals.

ANOVA showed that the differences were essentially between canals prepared with the Gates Glidden burs and those prepared with all the rotary systems, especially ProFile. 
Table 2. Mean values $(\overrightarrow{\mathrm{x}})$ and standard deviation (SD) between groups with statistical different measurements $(\mathrm{p}<0.05)$.

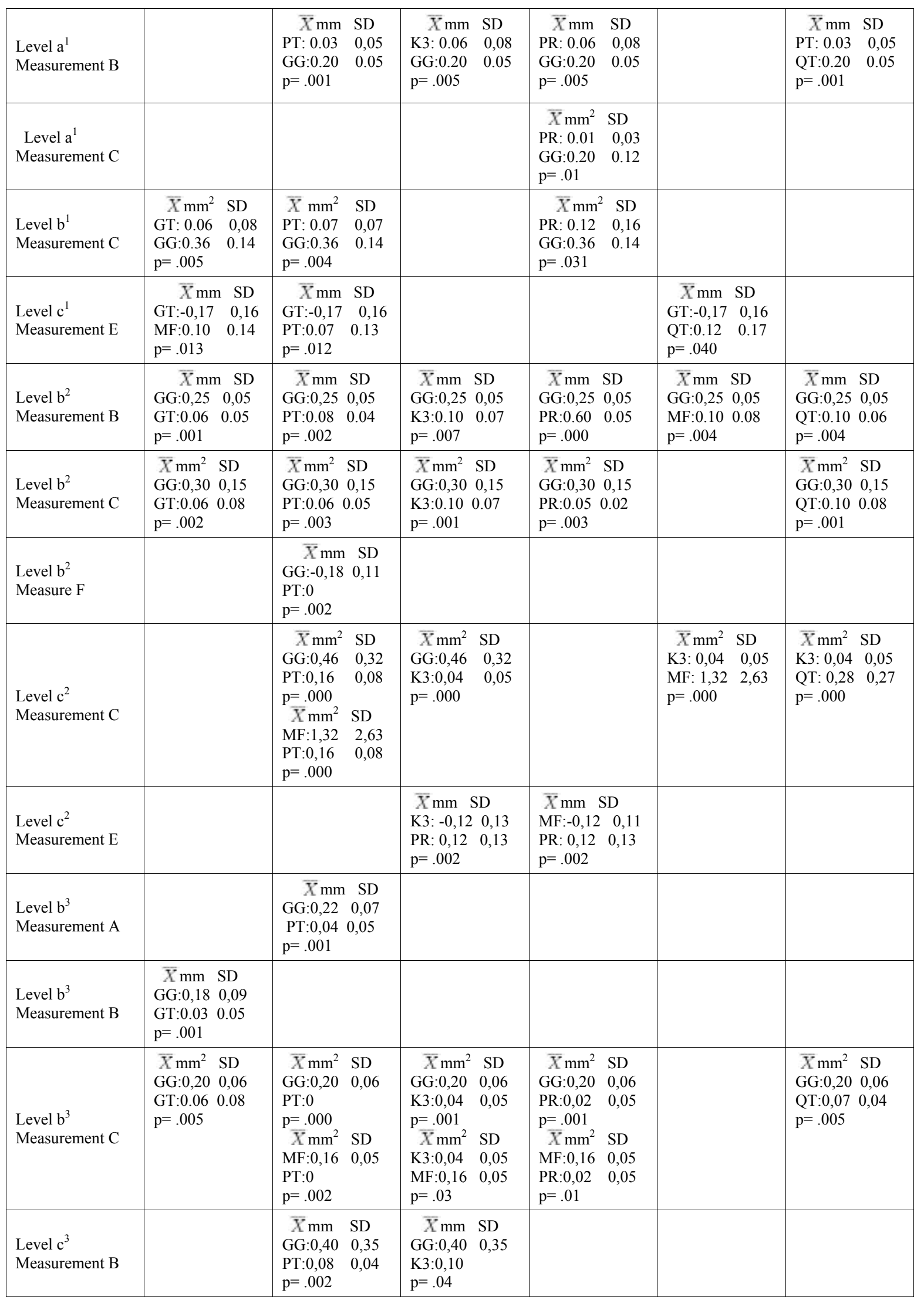

1 Disto-bucal canals; 2 Mesio-bucal canals; 3 Mesio-lingual canals

$\mathrm{GG}=$ Gates Glidden, $\mathrm{PT}=$ Protaper; $\mathrm{PR}=$ Profile, MF= MFile, QT=Quantec, K3=K3 


\section{Discussion}

Among different techniques used to study the behaviour of shaping endodontic instruments, CT shows ability to describe tridimensionally changes occurred inside the dental root canals, mainly in the medium and coronal thirds where orifice openers work.

The CT equipment chosen improves on the properties of conventional CT (9). The resolution matrix in this study was 512 x 512, as in similar studies (10). The slice thickness in this study was $0.625 \mathrm{~mm}$ and the reconstruction resolution was $0.2 \mathrm{~mm}$, a thinner cross-section than in other studies $(9,11)$, where the slice thickness was 1 $\mathrm{mm}$. The equipment used is able to afford greater resolution to the images since the section is thinner. A previous study managed by authors showed the usefulness of the method (12). Micro-CT is also a technique which offers root slide images and 3D reconstructions and can provide pre- and post-instrumentation comparative figures with a very high resolution. This procedure has been used to study quantitative and qualitative changes induced by root canal shaping $(13,14)$; however getting $3 \mathrm{D}$ images is technically complex.

Few studies have centred on studying the changes made to the coronal area of the canals (15) and their consequences for the subsequent therapeutic shaping of the rest of the canal (16).

As regards the results, among those referring to diameter modification the changes were greater and more frequent in the A measurement (buco-lingual diameter) than in B (mesio-distal diameter) at all the height levels. In terms of the canal surface area measurement, enlargement was greater at the most coronal level and in the distal canals more than in the mesial canals. In most cases the significant differences were between the Gates Glidden burs and the other systems, as the former increase the diameters and surface areas of the canals, as well as their displacement, to a greater extent than the latter (measurements E, F, H and I).

All these differences can lead to considering the different way that instruments made of nickel-titanium and of stainless steel work since the Gates Glidden burs can be more aggressive than the rest of the instrument systems. In a similar study to this, Gluskin et al. (1) compared the effects of Gates Glidden burs and hand files with those of GT files in mesial canals of mandibular molars, observing the results with CT. They obtained similar results to this study, attributing them to the relative inflexibility of stainless steel which helps to thin the root walls in areas close to the furcation. According to another study (17), stainless steel instruments tend to straighten the canals in the cervical third. Preparation with nickel-titanium instruments respects the initial canals' own anatomy (18). Greater changes were detected with the Gates Glidden burs than with the GT instruments with a greater loss of working length produced with the former. According to these authors, the reason is that nickel-titanium files can stay more centred in the canal during instrumentation, minimising canal straightening. This supposition is supported by the findings of different authors and studies $(19,20)$, who observed that stainless steel files tend to straighten the canals.

The CT image diagnosis technique employed in this study is a non-invasive method for evaluating changes within the root canal system, with good reproducibility on comparing the measurements of points from the two CT acquisitions done. It has shown that stainless steel instruments are more aggressive than those made of nickel-titanium; Profile causes the least wear in the roots' coronal area; of the three cross-sections studied, the most coronal is the one that is modified the most by all the instruments.

\section{References}

1. Gluskin AH, Brown DC, Buchanan LS. A reconstructed computerized tomographic comparison of Ni-Ti rotary GT files versus traditional instruments in canals shaped by novice operators. Int Endod J. 2001;34:476-84.

2. Tachibana H, Matsumoto K. Applicability of X-ray computerized tomography in endodontics. Endod Dent Traumatol. 1990;6:16-20.

3. Jin GC, Lee SJ, Roh BD. Anatomical study of C-shaped canals in mandibular second molars by analysis of computed tomography. $\mathrm{J}$ Endod. 2006;32:10-3.

4. Taşdemir T, Aydemir H, Inan U, Unal O. Canal preparation with Hero 642 rotary Ni-Ti instruments compared with stainless steel hand K-file assessed using computed tomography. Int Endod J. 2005;38:402-8.

5. Peters OA, Barbakow F, Peters CI. An analysis of endodontic treatment with three nickel-titanium rotary root canal preparation techniques. Int Endod J. 2004;37:849-59.

6. Lazzaretti DN, Camargo BA, Della Bona A, Fornari VJ, Vanni JR, Baratto Filho F. Influence of different methods of cervical flaring on establishment of working length. J Appl Oral Sci. 2006;14:351-4.

7. Schmitz Mda S, Santos R, Capelli A, Jacobovitz M, Spanó JC, Pécora JD. Influence of cervical preflaring on determination of apical file size in mandibular molars: SEM analysis. Braz Dent J. 2008;19:245-51.

8. Carlsen O. Root complex and root canal system: a correlation analysis using one-rooted mandibular second molars. Scand J Dent Res. 1990;98:273-85.

9. Velvart P, Hecker H, Tillinger G. Detection of the apical lesion and the mandibular canal in conventional radiography and computed tomography. Oral Surg Oral Med Oral Pathol Oral Radiol Endod. 2001;92:682-8.

10. Garip Y, Günday M. The use of computed tomography when comparing nickel-titanium and stainless steel files during preparation of simulated curved canals. Int Endod J. 2001;34:452-7.

11. Vannier MW, Hildebolt CF, Conover G, Knapp RH, YokoyamaCrothers N, Wang G. Three-dimensional dental imaging by spiral CT. A progress report. Oral Surg Oral Med Oral Pathol Oral Radiol Endod. 1997;84:561-70.

12. Hervás García A, Forner Navarro L, Llena Puy MC, Zaragoza Cardells E. Cutting efficiency evaluation of Quantec Series 2000 orifice openers with computed tomography (CT). Med Oral Patol Oral Cir Bucal. 2008;13:E516-22.

13. Rhodes JS, Ford TR, Lynch JA, Liepins PJ, Curtis RV. A comparison of two nickel-titanium instrumentation techniques in teeth using microcomputed tomography. Int Endod J. 2000;33:279-85.

14. Peters OA, Laib A, Göhring TN, Barbakow F. Changes in root 
canal geometry after preparation assessed by high-resolution computed tomography. J Endod. 2001;27:1-6.

15. Berutti E. Computerized analysis of the instrumentation of the root canal system. J Endod. 1993;19:236-8.

16. Davis RD, Marshall JG, Baumgartner JC. Effect of early coronal flaring on working length change in curved canals using rotary nickel-titanium versus stainless steel instruments. J Endod. 2002;28:43842.

17. Tucker DM, Wenckus CS, Bentkover SK. Canal wall planning by engine-driven nickel-titanium instruments, compared with stainless-steel hand instrumentation. J Endod. 1997;23:170-3.

18. Kosa DA, Marshall G, Baumgartner JC. An analysis of canal centering using mechanical instrumentation techniques. J Endod. 1999;25:441-5.

19. Thompson SA, Dummer PM. Shaping ability of Hero 642 rotary nickel-titanium instruments in simulated root canals: Part 1. Int Endod J. 2000;33:248-54.

20. Bryant ST, Thompson SA, Al-Omari MA, Dummer PM. Shaping ability of Profile rotary nickel-titanium instruments with ISO sized tips in simulated root canals: Part 1. Int Endod J. 1998;31:275-81.

\section{Acknowledgements}

The authors thank the radiology company ERESA for the facilities given to use its CT equipment. They also wish to thank Mary Georgina Hardinge for translation assistance. 